Bulletin UASVM Food Science and Technology 70(1)/2013, 53-57

ISSN-L 2344-2344; Print ISSN 2344-2344; Electronic ISSN 2344-5300

\title{
The Influence of Hammer Type Used in Grinding Mills on Grist Fineness
}

\section{Mircea-Valentin MUNTEAN, Ovidiu MARIAN, Ovidiu RANTA, Ioan DROCAS, Giorgiana Mihaela CATUNESCU}

\author{
${ }^{1)}$ University of Agricultural Sciences and Veterinary Medicine, Faculty of Agriculture, 3-5 Manastur \\ street, Cluj-Napoca, Romania \\ mmvali@yahoo.com
}

\begin{abstract}
Hammer mills are machines used in agriculture graded to obtain concentrated fodder mix and food industry for grinding vegetable raw materials necessary for obtaining various types of flours. The hammer mills grinding materials is produced upon impact of the hammer material and crushing plate located inside the grinding chamber.

Depending on the hammers rotor assembly mode, the following types of mills can be used: hammer mills articulated and fixed hammer mills.

The objective of this paper is to study the influence of hammer profile during the operation of grinding wheat on hammer mills using the same sieve.
\end{abstract}

Keywords: agricultural, food, mills, grinding, hammer

\section{INTRODUCTION}

A research team from Technical Science and Soil Science Department of USAMV Cluj-Napoca, has carried during several years, studies of few agricultural machines made by several companies. Of these may be mentioned: rotary mowers, rotary rakes, spraying machines, feed mixers and hammer mills.

Grinding is the operation to reduce the geometrical dimensions of the particles by destroying their physical integrity, as a result of mechanical action on the material. Applications in the food industry are reflected in most branches of the food industry: milling, sugar rafinery, canned food, starch, alcohol, beer, wine, etc.

Grinding operation efficiency consists in the conversion with minimum power consumption and maximum productivity gave one solid material in a powdery or granular product size and shape required. Achieving this goal depends on a variety of factors:

- humidity is usually a negative factor with adverse effects on the process of crumbling;

- fineness of the material to be cut decreases productivity and increases the consumption of energy, so the cost of operation;

- the degree of crumbling (m) depends on the type of machine and the size of the pieces obtained:

$$
\mathrm{m}=\frac{\mathrm{d}_{1}}{\mathrm{~d}_{2}}
$$

Where: $d_{1}$ - size of the original material; $d_{2}$ - product size.

For large pieces the degree of crumbling $m$ take values from 2 to 25 , and to decrease the size of grinding can be reached at $\mathrm{m}=150$ (crumbling in several stages).

The aim of this paper is to study the influence of moisture during the operation of grinding wheat on hammer mills using the same sieve. 


\section{MATERIALS AND METHODS}

To experience used a hammer mill type MB 7.5 (7,5 kW electric engine power, productivity 0,7 tonne/hour). Material used to experience was a variety of wheat named Ariesan with two different humidity: $14 \%$ and 18\%. The mill we used two types of hammers, three different types of sieve used on mill (46-8 $\mathrm{mm})$. Sieving
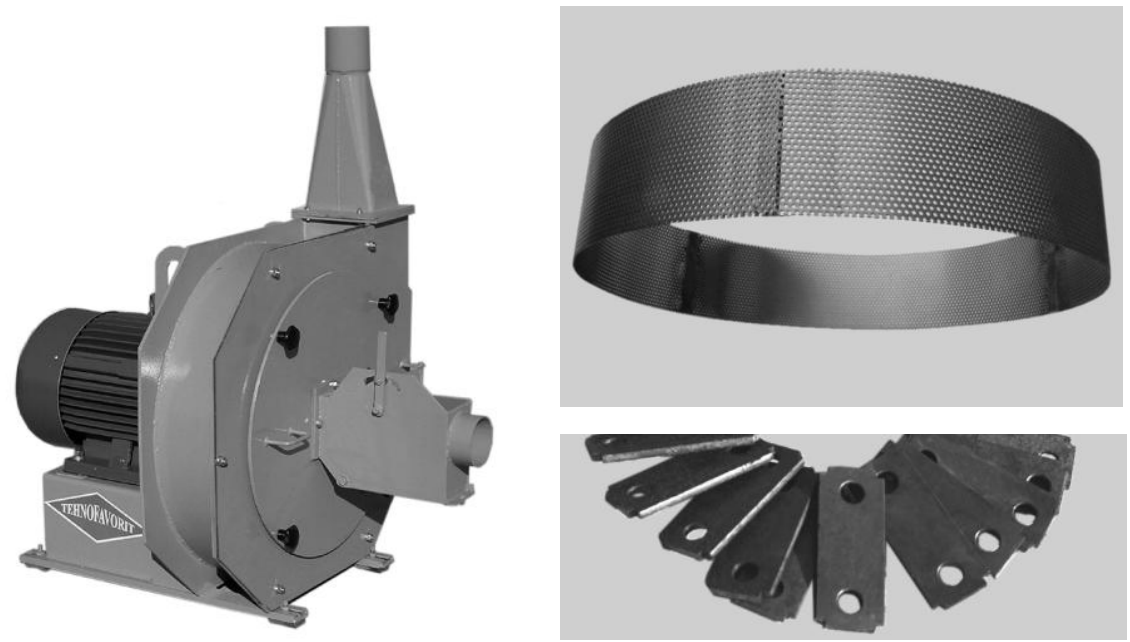

Fig.1. Hammers mill, sieve and hammers used on experiment

(sifting) is a mechanical operation realized trough separation in granulometric factions of some polidisperse mixtures of granules and powder on the basis of particle shape and size. For sifting was used a sieving machine AS 300 (Fig. 3). The grist result was separated using 4 types of sieve and 1 collector resulting 5 types of grist. From each sample was used a quantity of $500 \mathrm{~g}$ wheat.

For each determination using 3 samples at the same hammer, the same sieve and the

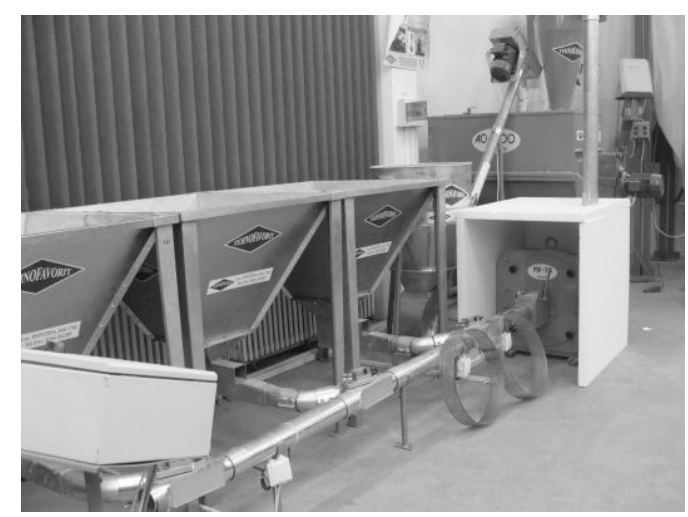

Fig. 2. The plant used for determination

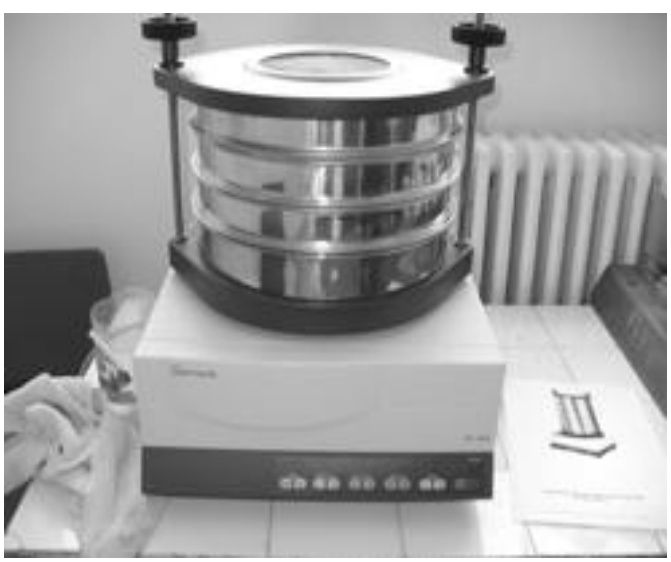

Fig. 3. Sieving machine AS 300

same moisture content resulting 36 values. Have been used the following notation: c1 hummer type 1; $\mathrm{c} 2$ - hummer type 2; Mill sieve mesh size are marked with the letter $\mathrm{M}$ with the following characteristics: M1 $-4 \mathrm{~mm}$ diameter, M2 $-6 \mathrm{~mm}$ diameter and M3 $-8 \mathrm{~mm}$ diameter; g1 humidity $1=14 \%, \mathrm{~g} 2$ humidity $=18 \%$. Sifting sieves are notated with: $\mathrm{s} 1-2.5$ $\mathrm{mm}, \mathrm{s} 2-1.25 \mathrm{~mm}, \mathrm{~s} 3-0.63 \mathrm{~mm}$ and $\mathrm{s} 4-0.25 \mathrm{~mm}$ diameter holes. Sieving machine working mode was set for each sample in part to be continuously 2 minutes with amplitude of vibration of $1.0 \mathrm{~mm} / \mathrm{g}$. 


\section{RESULTS AND DISCUSSIONS}

The grist result was classified using a four-site sieving machine with hole diameters between $2.5 \mathrm{~mm}$ and $0.25 \mathrm{~mm}$. Tab. 1 shows the comparative results obtained using two types of hammers for grinding wheat with mill sieve M1 at the $\mathrm{g} 1$ moisture and milling analysis obtained by sieving machine.

Tab. 1

The comparative results obtained using sieve M1 for $\mathrm{g} 1$ moisture of wheat

\begin{tabular}{|l|c|c|c|c|c|c|}
\hline \multicolumn{1}{|c|}{ Code } & $\mathbf{s 1}[\mathbf{g}]$ & $\mathbf{s 2}[\mathbf{g}]$ & $\mathbf{s 3} \mathbf{[ g ]}$ & $\mathbf{s 4} \mathbf{[ g ]}$ & collector $[\mathbf{g}]$ & total $[\mathbf{g}]$ \\
\hline c1M1g1 & 6 & 196 & 138 & 11 & 146 & 497 \\
\hline c1M1g1 & 14 & 176 & 131 & 13 & 164 & 498 \\
\hline c1M1g1 & 16 & 158 & 124 & 16 & 183 & 497 \\
\hline Total & $\mathbf{3 6}$ & $\mathbf{5 3 0}$ & $\mathbf{3 9 3}$ & $\mathbf{4 0}$ & $\mathbf{4 9 3}$ & $\mathbf{1 4 9 2}$ \\
\hline c2M1g1 & 1 & 150 & 192 & 14 & 139 & 496 \\
\hline c2M1g1 & 2 & 135 & 182 & 17 & 161 & 497 \\
\hline c2M1g1 & 4 & 121 & 172 & 21 & 180 & 498 \\
\hline Total & $\mathbf{7}$ & $\mathbf{4 0 6}$ & $\mathbf{5 4 6}$ & $\mathbf{5 2}$ & $\mathbf{4 8 0}$ & $\mathbf{1 4 9 1}$ \\
\hline
\end{tabular}

Tab. 2 shows the comparative results obtained using two types of hammers for grinding wheat with mill sieve M1 at the moisture $\mathrm{g} 2$ and milling analysis obtained by sieving machine.

Tab.2

The comparative results obtained using sieve M1 for $\mathrm{g} 2$ moisture of wheat

\begin{tabular}{|l|c|c|c|c|c|c|}
\hline \multicolumn{1}{|c|}{ Code } & $\mathbf{s 1}[\mathbf{g}]$ & $\mathbf{s 2}[\mathbf{g}]$ & $\mathbf{s 3}[\mathrm{g}]$ & $\mathbf{s 4}[\mathrm{g}]$ & collector $[\mathrm{g}]$ & total $[\mathrm{g}]$ \\
\hline c1M1g2 & 10 & 260 & 134 & 11 & 81 & 496 \\
\hline c1M1g2 & 12 & 234 & 127 & 13 & 111 & 497 \\
\hline c1M1g2 & 14 & 210 & 120 & 16 & 138 & 498 \\
\hline Total & $\mathbf{3 6}$ & $\mathbf{7 0 4}$ & $\mathbf{3 8 1}$ & $\mathbf{4 0}$ & $\mathbf{3 3 0}$ & $\mathbf{1 4 9 1}$ \\
\hline c2M1g2 & 6 & 183 & 166 & 11 & 131 & 497 \\
\hline c2M1g2 & 14 & 164 & 157 & 13 & 150 & 498 \\
\hline c2M1g2 & 16 & 147 & 149 & 16 & 169 & 497 \\
\hline Total & $\mathbf{3 6}$ & $\mathbf{4 9 4}$ & $\mathbf{4 7 2}$ & $\mathbf{4 0}$ & $\mathbf{4 5 0}$ & $\mathbf{1 4 9 2}$ \\
\hline
\end{tabular}

When using the first type of hammer c1, mill sieve M1 and g1 moisture compared with the second type of hammer c2 under the same conditions (Tab. 1) is obtained a greater amount of grist on the sieves s1, s2 (with dimensions larger holes) and collector but a smaller amount of grist on sieve S3 and S4. When humidity increases to the value g2 (Tab. 2) amount of grist in the sieve $\mathrm{s} 2$ increases in both cases using hammer $\mathrm{c} 2$ increases fine grist collector.

Tab. 3 shows the comparative results obtained using two types of hammers for grinding wheat with mill sieve M2 at the moisture $\mathrm{g} 1$ and milling analysis obtained by sieving machine.

Tab. 3

The comparative results obtained using sieve M2 for g1 moisture of wheat

\begin{tabular}{|l|c|c|c|c|c|c|}
\hline \multicolumn{1}{|c|}{ Code } & $\mathbf{s 1}[\mathbf{g}]$ & $\mathbf{s} 2[\mathbf{g}]$ & $\mathbf{s 3}[\mathbf{g}]$ & $\mathbf{s 4}[\mathbf{g}]$ & collector $[\mathbf{g}]$ & total $[\mathbf{g}]$ \\
\hline c1M2g1 & 8 & 235 & 153 & 13 & 88 & 497 \\
\hline c1M2g1 & 14 & 211 & 145 & 16 & 112 & 498 \\
\hline c1M2g1 & 16 & 189 & 137 & 20 & 135 & 497 \\
\hline Total & $\mathbf{3 8}$ & $\mathbf{6 3 5}$ & $\mathbf{4 3 5}$ & $\mathbf{4 9}$ & $\mathbf{3 3 5}$ & $\mathbf{1 4 9 2}$ \\
\hline c2M2g1 & 11 & 273 & 131 & 8 & 73 & 496 \\
\hline c2M2g1 & 13 & 245 & 124 & 10 & 105 & 497 \\
\hline c2M2g1 & 15 & 220 & 117 & 12 & 134 & 498 \\
\hline Total & $\mathbf{3 9}$ & $\mathbf{7 3 8}$ & $\mathbf{3 7 2}$ & $\mathbf{3 0}$ & $\mathbf{3 1 2}$ & $\mathbf{1 4 9 1}$ \\
\hline
\end{tabular}


Tab. 4 shows the comparative results obtained using two types of hammers for grinding wheat with mill sieve $\mathrm{M} 2$ at the moisture $\mathrm{g} 2$ and milling analysis obtained by sieving machine.

Tab. 4

The comparative results obtained using sieve M2 for g2 moisture of wheat

\begin{tabular}{|l|c|c|c|c|c|c|}
\hline \multicolumn{1}{|c|}{ Code } & $\mathbf{s 1}[\mathbf{g}]$ & $\mathbf{s 2}[\mathbf{g}]$ & $\mathbf{s 3}[\mathbf{g}]$ & $\mathbf{s 4}[\mathbf{g}]$ & collector $[\mathrm{g}]$ & total $[\mathbf{g}]$ \\
\hline c1M2g2 & 16 & 274 & 120 & 8 & 80 & 498 \\
\hline c1M2g2 & 19 & 246 & 114 & 10 & 108 & 497 \\
\hline c1M2g2 & 22 & 221 & 108 & 12 & 135 & 498 \\
\hline Total & $\mathbf{5 7}$ & $\mathbf{7 4 1}$ & $\mathbf{3 4 2}$ & $\mathbf{3 0}$ & $\mathbf{3 2 3}$ & $\mathbf{1 4 9 3}$ \\
\hline c2M2g2 & 14 & 244 & 133 & 9 & 98 & 498 \\
\hline c2M2g2 & 16 & 219 & 126 & 11 & 125 & 497 \\
\hline c2M2g2 & 19 & 197 & 119 & 13 & 150 & 498 \\
\hline Total & $\mathbf{4 9}$ & $\mathbf{6 6 0}$ & $\mathbf{3 7 8}$ & $\mathbf{3 3}$ & $\mathbf{3 7 3}$ & $\mathbf{1 4 9 3}$ \\
\hline
\end{tabular}

When using the second type of hammer $\mathrm{c} 2$, mill sieve M2 and g1 moisture compared with the first type of hammer $\mathrm{c} 1$ under the same conditions (Tab. 3) is obtained a greater amount of grist on the sieves s1, s2 (with dimensions larger holes) and a smaller amount of grist on sieve S3, S4 and collector. When humidity increases to the value g2 (Tab. 4) amount of grist in the sieve s1 and s2 increases using hammer $\mathrm{c} 2$ increases fine grist in $\mathrm{s} 3, \mathrm{~s} 4$ and collector.

Tab. 5 shows the comparative results obtained using two types of hammers for grinding wheat with mill sieve M3 at the moisture $\mathrm{g} 1$ and milling analysis obtained by sieving machine.

Tab. 5

The comparative results obtained using sieve M3 for $\mathrm{g} 1$ moisture of wheat

\begin{tabular}{|l|c|c|c|c|c|c|}
\hline Code & $\mathbf{s 1}[\mathbf{g}]$ & $\mathbf{S 2}[\mathbf{g}]$ & $\mathbf{s 3} \mathbf{~ [ g ]}$ & $\mathbf{s 4}[\mathbf{g}]$ & collector $[\mathbf{g}]$ & total [g] \\
\hline c1M3g1 & 18 & 292 & 111 & 8 & 69 & 498 \\
\hline c1M3g1 & 21 & 262 & 105 & 10 & 99 & 497 \\
\hline c1M3g1 & 25 & 235 & 99 & 12 & 127 & 498 \\
\hline Total & $\mathbf{6 4}$ & $\mathbf{7 8 9}$ & $\mathbf{3 1 5}$ & $\mathbf{3 0}$ & $\mathbf{2 9 5}$ & $\mathbf{1 4 9 3}$ \\
\hline c2M3g1 & 15 & 266 & 132 & 10 & 75 & 498 \\
\hline c2M3g1 & 18 & 239 & 125 & 12 & 103 & 497 \\
\hline c2M3g1 & 21 & 215 & 118 & 15 & 129 & 498 \\
\hline Total & $\mathbf{5 4}$ & $\mathbf{7 2 0}$ & $\mathbf{3 7 5}$ & $\mathbf{3 7}$ & $\mathbf{3 0 7}$ & $\mathbf{1 4 9 3}$ \\
\hline
\end{tabular}

Tab. 6 shows the comparative results obtained using two types of hammers for grinding wheat with mill sieve M2 at the moisture $\mathrm{g} 2$ and milling analysis obtained by sieving machine.

The comparative results obtained using sieve M2 for $\mathrm{g} 2$ moisture of wheat

Tab. 6

\begin{tabular}{|l|c|c|c|c|c|c|}
\hline \multicolumn{1}{|c|}{ Code } & $\mathbf{s 1}[\mathbf{g}]$ & $\mathbf{s 2}[\mathbf{g}]$ & $\mathbf{s 3}[\mathbf{g}]$ & $\mathbf{s 4}[\mathbf{g}]$ & collector [g] & total [g] \\
\hline c1M3g2 & 43 & 316 & 87 & 5 & 47 & 498 \\
\hline c1M3g2 & 51 & 284 & 82 & 6 & 74 & 497 \\
\hline c1M3g2 & 61 & 255 & 77 & 7 & 98 & 498 \\
\hline Total & $\mathbf{1 5 5}$ & $\mathbf{8 5 5}$ & $\mathbf{2 4 6}$ & $\mathbf{1 8}$ & $\mathbf{2 1 9}$ & $\mathbf{1 4 9 3}$ \\
\hline c2M3g2 & 44 & 324 & 83 & 3 & 45 & 499 \\
\hline c2M3g2 & 52 & 291 & 78 & 3 & 74 & 498 \\
\hline c2M3g2 & 62 & 261 & 74 & 3 & 97 & 497 \\
\hline Total & $\mathbf{1 5 8}$ & $\mathbf{8 7 6}$ & $\mathbf{2 3 5}$ & $\mathbf{9}$ & $\mathbf{2 1 6}$ & $\mathbf{1 4 9 4}$ \\
\hline
\end{tabular}

When using sieve M3 (double size M1) and hammer c1 at g1 moisture (Tab. 5) the grist from the sieve s1 and s2 is greater than c2 hammer used. On the sieve s3, s4 and 
collector when using $\mathrm{C} 2$ hammer to get more grist than with $\mathrm{c} 1$ hammer. When humidity increases to the value g2 (Tab. 6), hammer c2, the sieve s1 and s2 is greater than $\mathrm{c} 1$ hammer used in the same condition and decrease the value from $\mathrm{c} 3$ and $\mathrm{c} 4$ sieve.

\section{CONCLUSION}

Influence the type of hammer mill and the grist sieve obtained can be interpreted analysing experimental values presented in Tab. 1 to 6 . The moisture of wheat variety is very important for the quality and quantity of grist be influenced by the type of hammer used. Thus, for hammer type 1 greater amount of grist was obtained on the site s1, s2 and s3 and s4 Site and the second type of collector hammers. Grinding higher moisture grain with $\mathrm{g} 2$ was obtained on siev s2 a larger amount of grist for the mill sieve M. A lower moisture content $\mathrm{g} 1$ getting the collector caused a greater amounts of grist. In order to get a certain type of fineness of milling, material moisture must be chosen depending on the degree of grinding required.

\section{REFERENCES}

1. Banu, C. et al., (2002). p. 474 - 502. Manualul inginerului de industrie alimentara, Ed. Tehnica, Bucuresti.

2. Muntean, M. et al. (2008). Volume 65 (2). p. 291-295. Effect of intermittent vibration in the separation with sifting of mix polidisperse systems used in food industry and animal science, Bulletin of USAMV. ISSN 1843 - 5246

3. Rus, F., (2001). p. 190 - 192. Operatii de separare in industria alimentara, Ed. Universitatii Transilvania, Brasov. 